\title{
VIŠEKRITERIJUMSKI IZBOR DOBAVLJAČA PRIMENOM AHP METODOLOGIJE I SOFTVERSKOG PAKETA EXPERT CHOISE
}

\author{
Milan Stojanović1, \\ Predrag Popović1, \\ Željko Milovanović
}

\author{
${ }^{1}$ Univerzitet Singidunum, \\ Danijelova 32, \\ Beograd, Srbija \\ 2JKP „Vodovod” Zaječar, \\ Bulevar dr Zorana Đinđića 5, \\ Zaječar, Srbija
}

Correspondence:

Milan Stojanović

e-mail:

milan.stojanovic.13@singimail.rs

\begin{abstract}
Rezime:
Funkcija nabavke predstavlja jedan od najbitnijih celina određenog privrednog subjekta. Od uspeha ove funkcije u velikoj meri zavisi efikasnost i efektivnost preduzeća. U savremenim tržišnim uslovima, proces selekcije dobavljača predstavlja jedan od ključnih aktivnosti menadžmenta u okviru nabavke i okruženja lanca snabdevanja. Zadatak svih privrednih subjekata, bez obzira na delatnost, predstavlja zadovoljenje potreba. U cilju ostvarenja ovog zadatka, potrebno je imati dobre saradnike koji su finansijski stabilni, isporučuju robu na vreme, poseduju robu visokog kvaliteta koju plasiraju po niskim cenama. Predmet istraživanja rada predstavlja višekriterijumski izbor dobavljača primenom AHP metodologije uz pomoć softverskog paketa Expert Choice 11. Cilj istraživanja predstavlja rangiranje dobavljača na osnovu definisanih kriterijuma odlučivanja.
\end{abstract}

Ključne reči:

nabavka, izbor dobavljača, AHP metodologija, softver Expert Choice 11.

\section{UVOD}

U savremenim tržišnim uslovima, radi dostizanja optimalne konkurentske pozicije i uspeha na tržištu, potrebno je dostići visok nivo svih funkcija u okviru određenog privrednog subjekta. Moderni uslovi poslovanja zahtevaju od privrednog subjekta brzo prilagođavanje na promene u okruženju.

Naime, često se događa da dolazi do promene u potražnji i potrebama klijenata. U skladu sa kretanjima na tržištu, privrednim subjektima su potrebni adekvatni lanci snabdevanja. Agilan i optimalan lanac snabdevanja može da dovede do profita na turbulentnom tržištu.

Nabavka predstavlja primarnu funkciju za svaku organizaciju [1]. Celokupan proces nabavke ima veoma bitnu ulogu u svakodnevnom radu gotovo svih proizvodnih i uslužnih kompanija širom sveta. Različiti entiteti naručuju i kupuju različite kategorije sirovina, komponenti, poluproizvoda i gotovih proizvoda. Oni traže najefikasniji aranžman isporuke, koja se odražava na ukupnu profitabilnost i konkurentsku poziciju privrednih subjekata. Pored toga, lanci snabdevanja imaju jak uticaj i na zadovoljstvo i poverenje klijenata. Najveći uticaj na efikasnost sistema nabavke zavisi od pravilnog izbora odgovarajućih dobavljača [2]. 


\section{IZBOR DOBAVLJAČA}

Izbor dobavljača predstavlja aktivnost odabira dobavljača koji su u stanju da zadovolje potrebe kupovine preduzeća na dugi rok [3]. U osnovi, izbor dobavljača predstavlja proceduru odlučivanja sa ciljem smanjenja preliminarne grupe potencijalnih dobavljača do krajnjeg izbora jednog ili grupe dobavljača $[4,5,6,7,8]$.

Prilikom odabira dobavljača, potrebno je opredeliti i politiku organizacije u pogledu nabavke. Naime, određeni broj organizacija odlučuje se za odabir samo jednog dobavljača za određenu grupu proizvoda ili materijala, dok druga grupa privrednih subjekata vrši nabavku robe posredstvom dva ili više dobavljača. Svaka od opcija prilikom izbora dobavljača ima svoje prednosti i mane. Najčešći slučaj u praksi je korišćenje standarda 80:20, u kome se većina proizvoda iz određene grupe nabavlja od jednog dobavljača, dok se jedan manji deo nabavlja od drugog dobavljača.

Izbor dobavljača vrši se na osnovu kriterijuma za ocenu. Sami kriterijumi zavise od delatnosti preduzeća, količine robe koja se nabavlja i slično. Dikinson je 1966. godine identifikovao 23 različita kriterijuma za selekciju i evaluaciju distributera. Na osnovu ankete koju je sproveo u SAD i Kanadi, kvalitet, isporuka i istorija performansi identifikovani su kao tri najvažnija kriterijuma za izbor dobavljača, respektivno [9]. Prema Veberu, kvalitet je najvažniji kriterijum za izbor dobavljača. Nakon toga slede isporuka i troškovi [10]. Neki od autora napominju da je cena jedini kriterijum za odabir dobavljača. Međutim, Taluri i Narasiman zaključuju da cena nikako ne može biti jedini kriterijum prilikom izbora dobavljača [11]. Leman je predložio pet kriterijuma za odabir dobavljača: performanse, ekonomsko stanje, sporazum, društvene norme i troškove [12]. Kedik i Dejl sugerišu da kvalitet, plan proizvodnje, valjanost sistema kontrole, aktivnosti tokom istorije, kategorija stavke i cena moraju da se uključe u kriterijume za odabir dobavljača [13].

\section{IZBOR SOFTVERA}

Expert Choice 11 predstavlja jedan od najzastupljenijih i najefikasnijih softverskih alata za rešavanje problema višekriterijumskog odlučivanja. Expert Choice je softverski alat sa snažnim performansama za analizu odluka na nivou organizacije. Expert Choice je robusna aplikacija namenjena personalnim računarima kojim se stručnim organizacionim timovima omogućava prioritetno razvrstavanje, odnosno sortiranje alternativa i donošenje pouzdanih odluka o alternativama, sve zarad postizanja željenih ciljeva. Expert Choice omogućava integrisanje podataka iz različitih programa, kao što su Microsoft Excel i Microsoft Project.

Expert Choice softverski alat u potpunosti je prilagođen primeni analitički hijerarhijskom procesu (AHP metodi) i omogućava realizaciju svi neophodnih koraka.

Expert Choice je jedan od najefikasnijih alata za rešavanje problema višekriterijumskog odlučivanja. On omogućuje what if analizu pri strateškom planiranju proračuna projekata. Softver je u potpunosti prilagođen primeni AHP metode i podržava sve potrebne korake. Expert Choice dozvoljava strukturiranje problema i upoređivanje alternative i kriterijuma u parovima na više načina. Pored toga, on poseduje mogućnost sprovođenja analize osetljivosti pomoću jednostavne interaktivne razmene težina kriterijuma i alternative, ali i grafove za odličnu vizuelizaciju dobijenih rezultata [14].

Pomenuti softver podržava praktično neograničen broj kriterijuma i potkriterijuma i u potpunosti implementira Analitički hijerarhijski proces Tomasa Satija. U okruženju softvera Expert Choice, izgradnja modela predstavlja direktan proces. Expert Choice podržava ispitivanje konzistentnosti pri vrednovanju kriterijuma i alternativa prema definisanoj hijerarhiji, tako da se lako može pratiti kako promene prioriteta kriterijuma utiču na rangove alternativa [15].

\section{METODOLOGIJA ISTRAŽIVANJA}

Analitički hijerarhijski proces (eng. Analytical Hierarchy Process - AHP) razvijen je od strane Tomasa Satija. On predstavlja jednu od najčešće korišćenih višekriterijumskih metoda odlučivanja [16]. Proces izbora dobavljača pomoću AHP metode obuhvata šest koraka koji su prikazani na Slici 1. 


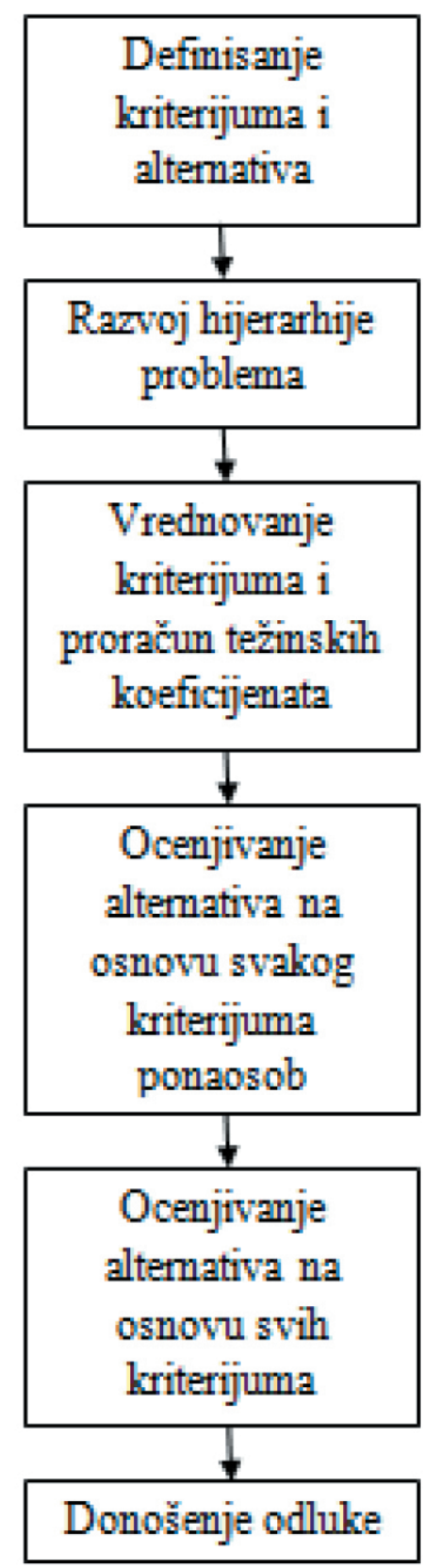

Slika 1. Proces izbora dobavljača primenom AHP metodologije

Prvi korak u primeni AHP metodologije podrazumeva definisanje kriterijuma i alternativa. U ovom primeru biće izvršeno upoređivanje 4 alternative (dobavljača), na osnovu 10 kriterijuma.

Razvoj hijerarhije problema predstavlja drugi korak u procesu izbora dobavljača primenom AHP metodologije. Hijerarhijska struktura problema odlučivanja prikazana je na Slici 2.

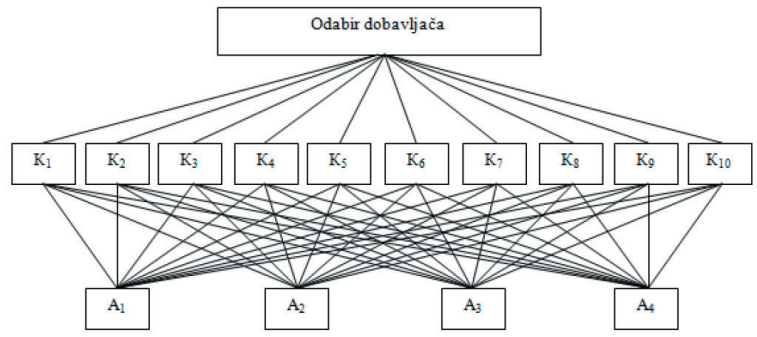

Slika 2. Hijerarhijska struktura problema odlučivanja

U trećem koraku istraživanja biće izvršeno vrednovanje kriterijuma za odabir dobavljača, čiji je cilj definisanje težinskih koeficijenata potrebnih za procenu i selekciju dobavljača. Vrednovanje kriterijuma vrši se na osnovu Satijeve devetostepene skale prikazane u Tabeli 1.

\begin{tabular}{ccc}
\hline $\begin{array}{c}\text { Nivo } \\
\text { važnosti }\end{array}$ & Definicija & Objašnjenje \\
\hline 1 & Jednaka važnost & $\begin{array}{c}\text { Dva faktora imaju isti } \\
\text { doprinos cilju }\end{array}$ \\
\hline 3 & Nešto važno & $\begin{array}{c}\text { Iskustvo i presuda } \\
\text { favorizuje jedno iznad } \\
\text { drugog }\end{array}$ \\
\hline 5 & Mnogo važnije & $\begin{array}{c}\text { Iskustvo i presuda } \\
\text { snažno favorizuju jedno } \\
\text { iznad drugog }\end{array}$ \\
\hline 9 & Veoma mnogo važnije & $\begin{array}{c}\text { Iskustvo i presuda } \\
\text { snažno favorizuju jedno } \\
\text { iznad drugog }\end{array}$ \\
\hline $2-4-6-8$ & Apsolutno važnije & $\begin{array}{c}\text { Iskustvo i presuda apso- } \\
\text { lutno favorizuju jedno } \\
\text { iznad drugog }\end{array}$ \\
\hline
\end{tabular}

Tabela 1. Satijeva skala

Izvor: [17]

Ocenjivanje alternativa na osnovu svakog kriterijuma je četvrti korak. U njemu će svaka od 4 alternative biti ocenjena na osnovu svih 10 razmatranih kriterijuma odlučivanja.

U petom koraku vrši se ocenjivanje alternativa na osnovu svih kriterijuma. U toku ovog koraka svaka od alternativa dobija svoju vrednost.

Šesti korak podrazumeva donošenje odluke i izbora alternativa. Prilikom odabira, dobavljač sa najvećim stepenom vrednošću predstavlja najpovoljnije rešenje za određeni privredni subjekat. 


\section{REZULTATII DISKUSIJA}

Privredni subjekt iz Beograda bavi se prodajom robe široke potrošnje na malo. U cilju optimizacije troškova i poboljšanja upravljanja zalihama, kompanija razmatra dobavljača za jednu grupu proizvoda. Prvim krugom analize, od velikog broja dobavljača izabrano je četiri $\left(A_{1}\right.$, $\left.A_{2}, A_{3}, A_{4}\right)$ koji su uzeti u razmatranje u drugom krugu odabira. Upoređivanje dobavljača biće izvršeno na osnovu 10 kriterijuma datih u Tabeli 2 .

\begin{tabular}{cc}
\hline Obeležje & Pun naziv kriterijuma \\
\hline $\mathrm{K}_{1}$ & Kvalitet proizvoda \\
\hline $\mathrm{K}_{2}$ & Cena \\
\hline $\mathrm{K}_{3}$ & Troškovi transporta \\
\hline $\mathrm{K}_{4}$ & Rok isporuke \\
\hline $\mathrm{K}_{5}$ & Asortiman proizvoda \\
\hline $\mathrm{K}_{6}$ & Pouzdanost \\
\hline $\mathrm{K}_{7}$ & Tehnonsijska stabilnost \\
\hline $\mathrm{K}_{8}$ & Geogrka sposobnost \\
\hline $\mathrm{K}_{9}$ & Usaglašenost proizvoda sa standardima ekologije \\
\hline $\mathrm{K}_{10}$ &
\end{tabular}

Tabela 2. Kriterijumi za odabir dobavljača

\section{Nivo 1}

Zaposleni u funkciji nabavke u koordinaciji i saradnji sa direktorom organizacije imaju zadatak da ocene razmatrane dobavljače na osnovu pomenutih kriterijuma. Ocenjivanje je izvršeno u skladu sa Satijevom devetostepenom skalom. Poređenje kriterijuma i normalizacija sopstvenog vektora prikazano je u Tabeli 3.

Konačni prioritet za Nivo 1: $\mathrm{K}_{1}(0,2886) ; \mathrm{K}_{2}(0,2103)$; $\mathrm{K}_{4}(0,1517) ; \mathrm{K}_{7}(0,1096) ; \mathrm{K}_{8}(0,0789) ; \mathrm{K}_{3}(0,0566) ; \mathrm{K}_{6}$ $(0,0402) ; K_{5}(0,0283) ; K_{10}(0,0203) ; K_{9}(0,0154)$.

\section{Nivo 2}

Nakon ocenjivanja kriterijuma, menadžeri nabavke u saradnji sa direktorom ocenjuju dobavljače na osnovu svakog kriterijuma ponaosob.

\begin{tabular}{ccccccc}
\hline $\begin{array}{c}\text { Kriterijum } \\
\mathbf{K}_{\mathbf{1}}\end{array}$ & $\mathbf{A}_{\mathbf{1}}$ & $\mathbf{A}_{2}$ & $\mathbf{A}_{3}$ & $\mathbf{A}_{4}$ & $\boldsymbol{\Sigma}$ & Rang \\
\hline $\mathrm{A}_{1}$ & 0,1538 & 0,2000 & 0,1587 & 0,1305 & 0,6430 & 0,1608 \\
\hline $\mathrm{A}_{2}$ & 0,0769 & 0,1000 & 0,1202 & 0,0862 & 0,3833 & 0,0958 \\
\hline $\mathrm{A}_{3}$ & 0,4615 & 0,4000 & 0,4808 & 0,5222 & 1,8645 & 0,4661 \\
\hline $\mathrm{A}_{4}$ & 0,3077 & 0,3000 & 0,2404 & 0,2611 & 1,1092 & 0,2773 \\
\hline
\end{tabular}

Tabela 4. Određivanje normalizovanog sopstvenog vektora na osnovu kriterijuma $\mathrm{K}_{1}$

Konačni prioritet za kriterijum $\mathrm{K}_{1}: \mathrm{A}_{3}(0,4661) ; \mathrm{A}_{4}$ $(0,2773) ; A_{1}(0,1608) ; A_{2}(0,0958)$.

\begin{tabular}{ccccccc}
\hline $\begin{array}{c}\text { Kriterijum } \\
\mathrm{K}_{2}\end{array}$ & $\mathrm{~A}_{1}$ & $\mathrm{~A}_{2}$ & $\mathrm{~A}_{3}$ & $\mathrm{~A}_{4}$ & $\sum$ & Rang \\
\hline $\mathrm{A}_{1}$ & 0,1580 & 0,1626 & 0,1333 & 0,2308 & 0,6846 & 0,1712 \\
\hline $\mathrm{A}_{2}$ & 0,4739 & 0,4926 & 0,5333 & 0,3846 & 1,8845 & 0,4711 \\
\hline $\mathrm{A}_{3}$ & 0,3160 & 0,2463 & 0,2667 & 0,3077 & 1,1366 & 0,2842 \\
\hline $\mathrm{A}_{4}$ & 0,0521 & 0,0985 & 0,0667 & 0,0769 & 0,2942 & 0,0736 \\
\hline
\end{tabular}

Tabela 5. Određivanje normalizovanog sopstvenog vektora na osnovu kriterijuma $\mathrm{K}_{2}$

Konačni prioritet za kriterijum $\mathrm{K}_{2}: \mathrm{A}_{2}(0,4711) ; \mathrm{A}_{3}$ $(0,2842) ; \mathrm{A}_{1}(0,1712) ; \mathrm{A}_{4}(0,0736)$.

\begin{tabular}{ccccccc}
\hline $\begin{array}{c}\text { Kriterijum } \\
\mathbf{K}_{3}\end{array}$ & $\mathbf{A}_{1}$ & $\mathbf{A}_{2}$ & $\mathbf{A}_{3}$ & $\mathbf{A}_{4}$ & $\boldsymbol{\Sigma}$ & Rang \\
\hline $\mathrm{A}_{1}$ & 0,2611 & 0,3000 & 0,2404 & 0,3077 & 1,1092 & 0,2773 \\
\hline $\mathrm{A}_{2}$ & 0,0862 & 0,1000 & 0,1202 & 0,0769 & 0,3833 & 0,0958 \\
\hline $\mathrm{A}_{3}$ & 0,5222 & 0,4000 & 0,4808 & 0,4615 & 1,8645 & 0,4661 \\
\hline $\mathrm{A}_{4}$ & 0,1305 & 0,2000 & 0,1587 & 0,1538 & 0,6430 & 0,1608 \\
\hline
\end{tabular}

Tabela 6. Određivanje normalizovanog sopstvenog vektora na osnovu kriterijuma $\mathrm{K}_{3}$

Konačni prioritet za kriterijum $\mathrm{K}_{3}: \mathrm{A}_{3}(0,4661) ; \mathrm{A}_{1}$ $(0,2773) ; \mathrm{A}_{4}(0,1608) ; \mathrm{A}_{2}(0,0958)$.

\begin{tabular}{ccccccc}
\hline $\begin{array}{c}\text { Kriterijum } \\
\mathbf{K}_{4}\end{array}$ & $\mathbf{A}_{\mathbf{1}}$ & $\mathbf{A}_{\mathbf{2}}$ & $\mathbf{A}_{\mathbf{3}}$ & $\mathbf{A}_{4}$ & $\boldsymbol{\Sigma}$ & Rang \\
\hline $\mathrm{A}_{1}$ & 0,1000 & 0,0862 & 0,0769 & 0,1202 & 0,3833 & 0,0958 \\
\hline $\mathrm{A}_{2}$ & 0,3000 & 0,2611 & 0,3077 & 0,2404 & 1,1092 & 0,2773 \\
\hline $\mathrm{A}_{3}$ & 0,2000 & 0,1305 & 0,1538 & 0,1587 & 0,6430 & 0,1608 \\
\hline $\mathrm{A}_{4}$ & 0,4000 & 0,5222 & 0,4615 & 0,4808 & 1,8645 & 0,4661 \\
\hline
\end{tabular}

Tabela 7. Određivanje normalizovanog sopstvenog vektora na osnovu kriterijuma $\mathrm{K}_{4}$

Konačni prioritet za kriterijum $\mathrm{K}_{4}: \mathrm{A}_{4}(0,4661) ; \mathrm{A}_{2}$ $(0,2773) ; A_{3}(0,1608) ; A_{1}(0,0958)$. 


\begin{tabular}{|c|c|c|c|c|c|c|c|c|c|c|}
\hline 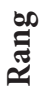 & $\begin{array}{l}0 \\
\infty \\
\infty \\
\text { î } \\
0\end{array}$ & 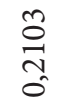 & 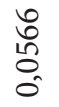 & $\begin{array}{l}\hat{n} \\
\stackrel{n}{0}\end{array}$ & 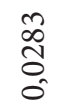 & $\begin{array}{l}\text { ô } \\
\text { †े } \\
0 \\
0\end{array}$ & $\begin{array}{l}\stackrel{0}{0} \\
0 \\
0\end{array}$ & $\begin{array}{l}\text { aे } \\
\hat{0} \\
0\end{array}$ & $\begin{array}{l}\text { 苟 } \\
0 \\
0\end{array}$ & $\begin{array}{l}\text { ro } \\
\text { d. } \\
0\end{array}$ \\
\hline$\omega$ & $\begin{array}{l}\overrightarrow{0} \\
\infty \\
\infty \\
0\end{array}$ & 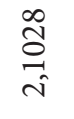 & $\begin{array}{l}\text { H' } \\
\text { L } \\
1 \\
0\end{array}$ & $\stackrel{+}{\stackrel{+}{n}}$ & 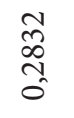 & $\begin{array}{l}\infty \\
\stackrel{\infty}{+} \\
\text { +1 } \\
0\end{array}$ & $\begin{array}{l}\text { \& } \\
\text { ᄋ̆ } \\
-1\end{array}$ & $\begin{array}{l}\text { मे } \\
\stackrel{0}{0} \\
0\end{array}$ & $\begin{array}{l}\frac{H}{6} \\
\text { 点 }\end{array}$ & $\begin{array}{l}\text { İ } \\
\text { స్ } \\
\text { o }\end{array}$ \\
\hline$x^{2}$ & $\begin{array}{l}\frac{\infty}{\hat{\sigma}} \\
\stackrel{-}{0}\end{array}$ & $\begin{array}{l}\stackrel{\infty}{\stackrel{\rho}{2}} \\
\stackrel{-}{0}\end{array}$ & $\begin{array}{l}2 \\
\hat{0} \\
0 \\
0 \\
0\end{array}$ & $\begin{array}{l}\infty \\
\hat{n} \\
\stackrel{n}{0} \\
0\end{array}$ & $\begin{array}{l}\text { 栾 } \\
\text { O } \\
0\end{array}$ & 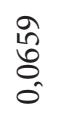 & $\begin{array}{l}\vec{m} \\
\overrightarrow{0}\end{array}$ & $\begin{array}{l}\hat{\partial} \\
\hat{0} \\
0 \\
0\end{array}$ & $\begin{array}{l}\stackrel{0}{0} \\
\overrightarrow{0}\end{array}$ & $\begin{array}{l}\text { ते } \\
\text { O. } \\
\text { O. }\end{array}$ \\
\hline$z^{a}$ & $\begin{array}{l}\hat{0} \\
0 \\
0 \\
0\end{array}$ & $\begin{array}{l}\hat{0} \\
\stackrel{0}{0} \\
\hat{0}\end{array}$ & $\begin{array}{l}\stackrel{2}{ } \\
\text { oे } \\
0 \\
0\end{array}$ & $\begin{array}{l}\stackrel{\infty}{\infty} \\
\stackrel{+}{0}\end{array}$ & 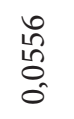 & $\begin{array}{l}\text { F } \\
\hat{O} \\
0\end{array}$ & 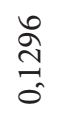 & $\begin{array}{l}\exists \\
\exists\end{array}$ & $\begin{array}{l}0 \\
\infty \\
0 \\
0 \\
0\end{array}$ & $\begin{array}{l}\text { R } \\
\text { ô } \\
0 \\
0\end{array}$ \\
\hline $\mathbb{Z}^{\infty}$ & $\begin{array}{l}\text { P } \\
\text { Oे } \\
\text { o } \\
0\end{array}$ & 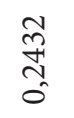 & $\begin{array}{l}\text { H' } \\
\text { Oे } \\
0 \\
0\end{array}$ & $\frac{\underset{\infty}{+}}{\stackrel{\infty}{0}}$ & $\begin{array}{l}\tilde{N} \\
0 \\
0 \\
0\end{array}$ & $\begin{array}{l}\overrightarrow{\tilde{H}} \\
\text { o. } \\
\text { o. }\end{array}$ & $\begin{array}{l}\frac{0}{\sim} \\
\frac{1}{0}\end{array}$ & $\begin{array}{l}\infty \\
0 \\
0 \\
0 \\
0\end{array}$ & $\begin{array}{l}0 \\
0 \\
0 \\
0 \\
0\end{array}$ & $\begin{array}{l}\underset{N}{\sigma} \\
0 \\
0\end{array}$ \\
\hline$\approx$ & $\begin{array}{l}\vec{n} \\
\stackrel{5}{m} \\
\text { ô }\end{array}$ & $\begin{array}{l}\infty \\
\infty \\
\stackrel{0}{N} \\
0 \\
0\end{array}$ & 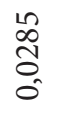 & $\begin{array}{l}\stackrel{2}{N} \\
\stackrel{0}{0}\end{array}$ & $\begin{array}{l}\stackrel{N}{\hat{0}} \\
0 \\
0\end{array}$ & $\begin{array}{l}0 \\
\stackrel{1}{0} \\
0 \\
0\end{array}$ & $\begin{array}{l}0 \\
0 \\
0 \\
0\end{array}$ & \begin{tabular}{l}
$\overrightarrow{3}$ \\
\multirow{0}{0}{} \\
0
\end{tabular} & $\begin{array}{l}\overrightarrow{\widetilde{I}} \\
\stackrel{0}{0}\end{array}$ & $\begin{array}{l}\text { ff } \\
\text { : } \\
0\end{array}$ \\
\hline$x^{\circ}$ & 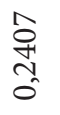 & $\begin{array}{l}\text { ôे } \\
\text { ठै. } \\
\hat{0}\end{array}$ & $\begin{array}{l}\infty \\
\infty \\
0 \\
0 \\
0\end{array}$ & $\underset{\vec{D}}{\stackrel{2}{0}}$ & $\begin{array}{l}\mathbb{N} \\
\stackrel{1}{0} \\
0\end{array}$ & \begin{tabular}{l}
\multirow{H}{*}{} \\
Oे \\
0
\end{tabular} & $\begin{array}{l}0 \\
\stackrel{0}{0} \\
0 \\
0\end{array}$ & $\begin{array}{l}\text { N̂ } \\
\stackrel{0}{0} \\
0\end{array}$ & $\begin{array}{l}0 \\
\& \\
0 \\
0\end{array}$ & $\begin{array}{l}m \\
0 \\
0\end{array}$ \\
\hline$\underbrace{n}$ & $\begin{array}{l}\text { N } \\
\text { ㄱ. } \\
\text { - }\end{array}$ & $\begin{array}{l}\vec{D} \\
\stackrel{0}{0}\end{array}$ & $\begin{array}{l}10 \\
0 \\
0 \\
0\end{array}$ & $\begin{array}{l}\text { ते } \\
\stackrel{0}{0}\end{array}$ & $\begin{array}{l}\text { Na } \\
\hat{O} \\
0\end{array}$ & $\begin{array}{l}\text { Hै } \\
\text { है } \\
0 \\
0\end{array}$ & $\begin{array}{l}\infty \\
\stackrel{\infty}{n} \\
\stackrel{0}{0}\end{array}$ & $\begin{array}{l}0 \\
\infty \\
\stackrel{0}{0} \\
0\end{array}$ & $\begin{array}{l}8 \\
8 \\
8 \\
0 \\
0\end{array}$ & $\begin{array}{l}0 \\
\stackrel{m}{0} \\
0 \\
0\end{array}$ \\
\hline$\underbrace{*}$ & 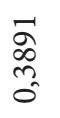 & 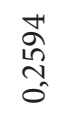 & $\begin{array}{l}\stackrel{\sim}{\approx} \\
\text { Oे } \\
0\end{array}$ & $\frac{\hat{\mathrm{N}}}{\stackrel{\mathrm{O}}{0}}$ & $\begin{array}{l}\text { त् } \\
\text { O } \\
0\end{array}$ & 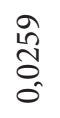 & $\begin{array}{l}\text { ఫे } \\
\text { ठ } \\
0\end{array}$ & $\begin{array}{l}\infty \\
\text { Jै } \\
0 \\
0\end{array}$ & $\begin{array}{l}0 \\
i n \\
0 \\
0 \\
0\end{array}$ & $\begin{array}{l}0 \\
\infty \\
0 \\
0 \\
0\end{array}$ \\
\hline$v^{m}$ & $\begin{array}{l}\hat{\sigma} \\
\text { ָे } \\
\hat{0}\end{array}$ & 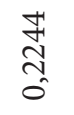 & $\begin{array}{l}\stackrel{g}{+} \\
\text { O } \\
0\end{array}$ & $\begin{array}{l}\frac{2}{\Omega} \\
\frac{1}{0}\end{array}$ & $\begin{array}{l}\underset{+}{+} \\
\stackrel{0}{0}\end{array}$ & 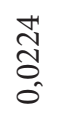 & $\begin{array}{l}\stackrel{0}{1} \\
\stackrel{m}{0} \\
0\end{array}$ & $\begin{array}{l}\infty \\
0 \\
0 \\
0\end{array}$ & $\begin{array}{l}\text { ̊े } \\
\text { ठ } \\
0\end{array}$ & $\begin{array}{l}\frac{1}{3} \\
0 \\
0\end{array}$ \\
\hline$\underbrace{N}$ & 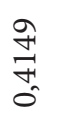 & 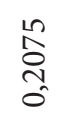 & $\begin{array}{l}\stackrel{n}{Z} \\
\overrightarrow{0} \\
0\end{array}$ & $\begin{array}{l}\hat{n} \\
\stackrel{0}{0} \\
\hat{0}\end{array}$ & $\begin{array}{l}\text { ̊े } \\
\text { ठิ } \\
\text { O }\end{array}$ & $\begin{array}{l}\tilde{n} \\
\tilde{n} \\
0 \\
0\end{array}$ & $\begin{array}{l}10 \\
0 \\
0 \\
0 \\
0 \\
0\end{array}$ & $\begin{array}{l}\stackrel{0}{2} \\
\stackrel{2}{0} \\
0 \\
0\end{array}$ & 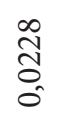 & $\begin{array}{l}\stackrel{\text { J }}{\mathrm{O}} \\
0 \\
0\end{array}$ \\
\hline 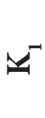 & $\begin{array}{l}\stackrel{m}{\not} \\
\stackrel{m}{0}\end{array}$ & $\begin{array}{l}\stackrel{2}{2} \\
\stackrel{-}{0}\end{array}$ & $\begin{array}{l}8 \\
\infty \\
0 \\
0 \\
0\end{array}$ & 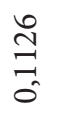 & $\begin{array}{l}\stackrel{0}{J} \\
\stackrel{+}{0} \\
0 \\
0\end{array}$ & $\begin{array}{l}\infty \\
\stackrel{\infty}{*} \\
0 \\
0\end{array}$ & $\begin{array}{l}\hat{1} \\
\hat{0} \\
0 \\
0 \\
0\end{array}$ & $\begin{array}{l}0 \\
\infty \\
\delta \\
0 \\
0\end{array}$ & $\begin{array}{l}\frac{1}{\hat{N}} \\
\hat{n} \\
0 \\
0\end{array}$ & $\begin{array}{l}n \\
\text { n } \\
0 \\
0 \\
0\end{array}$ \\
\hline & $\vec{u}$ & $\mathscr{V}^{N}$ & $v^{m}$ & $v^{*}$ & $x^{n}$ & $\forall^{\circ}$ & $\mathscr{y}$ & $\cup^{\infty}$ & $\forall^{\circ}$ & $\mathbb{Z}^{\circ}$ \\
\hline
\end{tabular}

Tabela 3. Određivanje normalizovanog sopstvenog vektor 


\begin{tabular}{ccccccc}
\hline $\begin{array}{c}\text { Kriterijum } \\
\mathbf{K}_{\mathbf{5}}\end{array}$ & $\mathbf{A}_{\mathbf{1}}$ & $\mathbf{A}_{\mathbf{2}}$ & $\mathbf{A}_{\mathbf{3}}$ & $\mathbf{A}_{\mathbf{4}}$ & $\boldsymbol{\Sigma}$ & Rang \\
\hline $\mathrm{A}_{1}$ & 0,4808 & 0,5222 & 0,4615 & 0,4000 & 1,8645 & 0,4661 \\
\hline $\mathrm{A}_{2}$ & 0,2404 & 0,2611 & 0,3077 & 0,3000 & 1,1092 & 0,2773 \\
\hline $\mathrm{A}_{3}$ & 0,1587 & 0,1305 & 0,1538 & 0,2000 & 0,6430 & 0,1608 \\
\hline $\mathrm{A}_{4}$ & 0,1202 & 0,0862 & 0,0769 & 0,1000 & 0,3833 & 0,0958 \\
\hline
\end{tabular}

Tabela 8. Određivanje normalizovanog sopstvenog vektora na osnovu kriterijuma $\mathrm{K}_{5}$

Konačni prioritet za kriterijum $\mathrm{K}_{5}$ : $\mathrm{A}_{1}(0,4661) ; \mathrm{A}_{2}$ $(0,2773) ; A_{3}(0,1608) ; A_{4}(0,0958)$.

\begin{tabular}{ccccccc}
\hline $\begin{array}{c}\text { Kriterijum } \\
\mathbf{K}_{\mathbf{6}}\end{array}$ & $\mathbf{A}_{\mathbf{1}}$ & $\mathbf{A}_{\mathbf{2}}$ & $\mathbf{A}_{\mathbf{3}}$ & $\mathbf{A}_{\mathbf{4}}$ & $\boldsymbol{\Sigma}$ & Rang \\
\hline $\mathrm{A}_{1}$ & 0,1000 & 0,1366 & 0,0683 & 0,0667 & 0,3716 & 0,0929 \\
\hline $\mathrm{A}_{2}$ & 0,4000 & 0,5464 & 0,6211 & 0,5333 & 2,1009 & 0,5252 \\
\hline $\mathrm{A}_{3}$ & 0,3000 & 0,1803 & 0,2070 & 0,2667 & 0,9540 & 0,2385 \\
\hline $\mathrm{A}_{4}$ & 0,2000 & 0,1366 & 0,1035 & 0,1333 & 0,5735 & 0,1434 \\
\hline
\end{tabular}

Tabela 9. Određivanje normalizovanog sopstvenog vektora na osnovu kriterijuma $\mathrm{K}_{6}$

Konačni prioritet za kriterijum $\mathrm{K}_{6}: \mathrm{A}_{2}(0,5252) ; \mathrm{A}_{3}$ $(0,2385) ; A_{4}(0,1434) ; A_{1}(0,0929)$.

\begin{tabular}{ccccccc}
\hline $\begin{array}{c}\text { Kriterijum } \\
\mathbf{K}_{7}\end{array}$ & $\mathbf{A}_{1}$ & $\mathbf{A}_{2}$ & $\mathbf{A}_{3}$ & $\mathbf{A}_{4}$ & $\boldsymbol{\Sigma}$ & Rang \\
\hline $\mathrm{A}_{1}$ & 0,2611 & 0,3077 & 0,2404 & 0,3000 & 1,1092 & 0,2773 \\
\hline $\mathrm{A}_{2}$ & 0,1305 & 0,1538 & 0,1587 & 0,2000 & 0,6430 & 0,1608 \\
\hline $\mathrm{A}_{3}$ & 0,5222 & 0,4615 & 0,4808 & 0,4000 & 1,8645 & 0,4661 \\
\hline $\mathrm{A}_{4}$ & 0,0802 & 0,0769 & 0,1202 & 0,1000 & 0,3833 & 0,0958 \\
\hline
\end{tabular}

Tabela 10. Određivanje normalizovanog sopstvenog vektora na osnovu kriterijuma $\mathrm{K}_{7}$

Konačni prioritet za kriterijum $\mathrm{K}_{7}$ : $\mathrm{A}_{3}(0,4661)$; $\mathrm{A}_{1}$ $(0,2773) ; A_{2}(0,1608) ; A_{4}(0,0958)$.

\begin{tabular}{ccccccc}
\hline $\begin{array}{c}\text { Kriterijum } \\
\mathbf{K} 8\end{array}$ & $\mathbf{A}_{1}$ & $\mathbf{A}_{2}$ & $\mathbf{A}_{3}$ & $\mathbf{A}_{4}$ & $\boldsymbol{\Sigma}$ & Rang \\
\hline $\mathrm{A}_{1}$ & 0,0769 & 0,0546 & 0,1124 & 0,0396 & 0,2835 & 0,0709 \\
\hline $\mathrm{A}_{2}$ & 0,3077 & 0,2183 & 0,1854 & 0,3601 & 1,0716 & 0,2679 \\
\hline $\mathrm{A}_{3}$ & 0,3846 & 0,6550 & 0,5618 & 0,4802 & 2,0816 & 0,5204 \\
\hline $\mathrm{A}_{4}$ & 0,2308 & 0,0721 & 0,1404 & 0,1200 & 0,5633 & 0,1408 \\
\hline
\end{tabular}

Tabela 11. Određivanje normalizovanog sopstvenog vektora na osnovu kriterijuma $\mathrm{K}_{8}$
Konačni prioritet za kriterijum $\mathrm{K}_{8}: \mathrm{A}_{3}(0,5204) ; \mathrm{A}_{2}$ (0,2679); $A_{4}(0,1408) ; A_{1}(0,0709)$.

\begin{tabular}{ccccccc}
\hline $\begin{array}{c}\text { Kriterijum } \\
\mathbf{K}\end{array}$ & $\mathbf{A}_{\mathbf{1}}$ & $\mathbf{A}_{2}$ & $\mathbf{A}_{3}$ & $\mathbf{A}_{4}$ & $\boldsymbol{\Sigma}$ & Rang \\
\hline $\mathrm{A}_{1}$ & 0,2183 & 0,3077 & 0,4093 & 0,1774 & 1,1127 & 0,2782 \\
\hline $\mathrm{A}_{2}$ & 0,0546 & 0,0769 & 0,0450 & 0,1075 & 0,2841 & 0,0710 \\
\hline $\mathrm{A}_{3}$ & 0,0721 & 0,2308 & 0,1364 & 0,1774 & 0,6167 & 0,1542 \\
\hline $\mathrm{A}_{4}$ & 0,6550 & 0,3846 & 0,4093 & 0,5376 & 1,9865 & 0,4966 \\
\hline
\end{tabular}

Tabela 12. Određivanje normalizovanog sopstvenog vektora na osnovu kriterijuma $\mathrm{K}_{9}$

Konačni prioritet za kriterijum $\mathrm{K}_{9}$ : $\mathrm{A}_{4}(0,4966) ; \mathrm{A}_{1}$ $(0,2782) ; A_{3}(0,1542) ; A_{2}(0,0710)$.

\begin{tabular}{ccccccc}
\hline $\begin{array}{c}\text { Kriterijum } \\
\text { Kio }\end{array}$ & $\mathbf{A}_{1}$ & $\mathbf{A}_{2}$ & $\mathbf{A}_{3}$ & $\mathbf{A}_{4}$ & $\boldsymbol{\Sigma}$ & Rang \\
\hline $\mathrm{A}_{1}$ & 0,2183 & 0,3529 & 0,1854 & 0,3333 & 1,0900 & 0,2725 \\
\hline $\mathrm{A}_{2}$ & 0,0721 & 0,1176 & 0,1404 & 0,1667 & 0,4968 & 0,1242 \\
\hline $\mathrm{A}_{3}$ & 0,6550 & 0,4706 & 0,5618 & 0,4167 & 2,1041 & 0,5260 \\
\hline $\mathrm{A}_{4}$ & 0,0546 & 0,0588 & 0,1124 & 0,0833 & 0,3091 & 0,0773 \\
\hline
\end{tabular}

Tabela 13. Određivanje normalizovanog sopstvenog vektora na osnovu kriterijuma $\mathrm{K}_{10}$

Konačni prioritet za kriterijum $\mathrm{K}_{10}$ : A3 (0,5260); $\mathrm{A}_{1}$ $(0,2725) ; A_{2}(0,1242) ; A_{4}(0,0773)$.

Nivo 3

Sledeći korak u primeni AHP metodologije predstavlja upoređivanje alternativa (dobavljača) na osnovu svih kriterijuma. Sinteza problema rangiranja dobavljača jednaka je zbiru proizvoda težina u okviru posmatranog kriterijuma.

Alternativa $\mathrm{A}_{1}$

$T_{A 1}=K_{1} * K_{1} A_{1}+K_{2} * K_{2} A_{1}+K_{3} * K_{3} A_{1}+K_{4} * K_{4} A_{1}+K_{5} * K_{5} A_{1}+K_{6} *$

$K_{6} A_{1}+K_{7} * K_{7} A_{1}+K_{8} * K_{8} A_{1}+K_{9} * K_{9} A_{1}+K_{10} * K_{10} A_{1}$

$T_{A 1}=0,2886 * 0,1608+0,2103 * 0,1712+0,0566 * 0,2773+0,1517 *$ $0,0958+0,0283 * 0,4661+0,0402 * 0,0929+0,1096 * 0,2773+0,0789$ $* 0,0709+0,0154 * 0,2782+0,0203 * 0,2725=0,1754$

Alternativa $\mathrm{A}_{2}$

$T_{A 2}=K_{1} * K_{1} A_{2}+K_{2} * K_{2} A_{2}+K_{3} * K_{3} A_{2}+K_{4} * K_{4} A_{2}+K_{5} * K_{5} A_{2}+K_{6} *$

$K_{6} A_{2}+K_{7} * K_{7} A_{2}+K_{8} * K_{8} A_{2}+K_{9} * K_{9} A_{2}+K_{10} * K_{10} A_{2}$

$T_{A 2}=0,2886 * 0,0958+0,2103 * 0,4711+0,0566 * 0,0958+0,1517 *$ $0,2773+0,0283 * 0,2773+0,0402 * 0,5252+0,1096 * 0,1608+0,0789 *$ $0,2679+0,0154 * 0,0710+0,0203 * 0,1242=0,2456$ 


\section{Alternativa $\mathrm{A}_{3}$}

$T_{A 3}=K_{1} * K_{1} A_{3}+K_{2} * K_{2} A_{3}+K_{3} * K_{3} A_{3}+K_{4} * K_{4} A_{3}+K_{5} * K_{5} A_{3}+K_{6} *$

$K_{6} A_{3}+K_{7} * K_{7} A_{3}+K_{8} * K_{8} A_{3}+K_{9} * K_{9} A_{3}+K_{10} * K_{10} A_{3}$

$T_{A 3}=0,2886 * 0,4661+0,2103 * 0,2842+0,0566 * 0,4661+0,1517 *$

$0,1608+0,0283 * 0,1608+0,0402 * 0,2385+0,1096 * 0,4661+0,0789 *$

$0,5204+0,0154 * 0,1542+0,0203 * 0,5260=0,3644$

Alternativa $\mathrm{A}_{4}$

$$
T_{A 4}=K_{1} * K_{1} A_{4}+K_{2} * K_{2} A_{4}+K_{3} * K_{3} A_{4}+K_{4} * K_{4} A_{4}+K_{5} * K_{5} A_{4}+K_{6} *
$$$$
K_{6} A_{4}+K_{7} * K_{7} A_{4}+K_{8} * K_{8} A_{4}+K_{9} * K_{9} A_{4}+K_{10} * K_{10} A_{4}
$$

$T_{A 4}=0,2886 * 0,2773+0,2103 * 0,0736+0,0566 * 0,1608+0,1517 *$ $0,4661+0,0283 * 0,0958+0,0402 * 0,1434+0,1096 * 0,0958+0,0789 *$ $0,1408+0,0154 * 0,4966+0,0733 * 0,0203=0,2147$

Ukupni rang dobavljača u odnosu na globalni cilj (kompozitni normalizovani vektor) je: $\mathrm{A}_{3}(0,3644) ; \mathrm{A}_{2}$ $(0,2456) ; A_{4}(0,2147) ; A_{1}(0,1754)$. Sveobuhvatna sinteza rangiranja dobavljača može biti predstavljena kao:

$$
T_{A 3}>T_{A 2}>T_{A 4}>T_{A 1}
$$

Pored standardnog načina primene, AHP metodologiju moguće je sprovesti i putem softverskih rešenja. Najpoznatiji softver za primenu AHP metodologije je Expert Choice. U cilju potvrde i sveobuhvatne analize problema, višekriterijumski izbor dobavljača primenom AHP metodologije izvršen je i putem softverskog rešenja Expert Choice.

Rezultati istraživanja prikazani su na Slici 3.

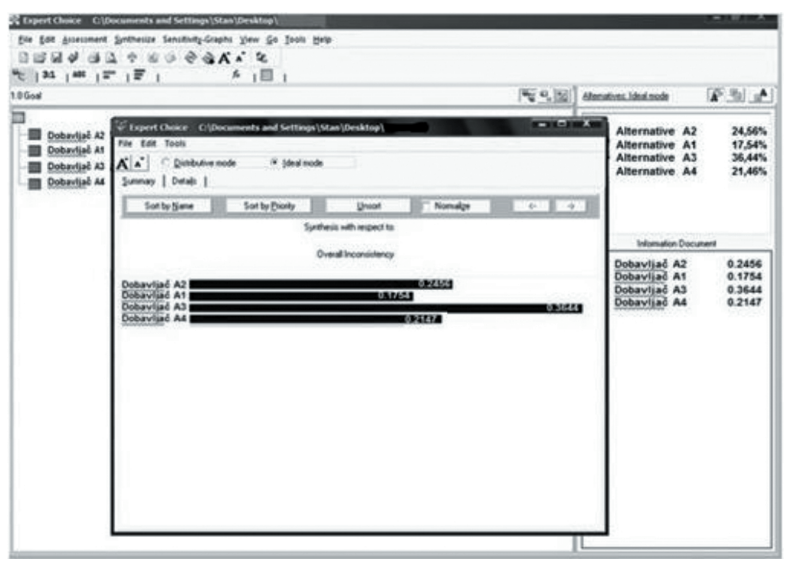

Slika 3. Rezultati istraživanja primenom Expert Choice-a

Rezultati istraživanja primenom softverskog paketa Expert Choice potvrdili su prvobitne rezultate izbora dobavljača. Konačni prioritet softverskog paketa Expert Choice moguće je prikazati na sledeći način: $\mathrm{A}_{3}(0,3644)$; $A_{2}(0,2456) ; A_{4}(0,2147) ; A_{1}(0,1754)$.

\section{ZAKLJUČAK}

U ovom radu izvršen je višekriterijumski odabir dobavljača za određenu grupu proizvoda široke potrošnje. Analizirano je četiri dobavljača na osnovu 10 kriterijuma i dobijeni su sledeći rezultati:

- Kriterijum sa najvećom važnošću za analizirano preduzeće je kriterijum $\mathrm{K}_{1}$ - kvalitet proizvoda sa ocenom 0,2886 , dok je na osnovu ocena donosioca odluka ustanovljeno da se najmanja pažnja pri izboru dobavljača ovog preduzeća pridaje kriterijumu usaglašenost proizvoda sa standardima ekologije sa ocenom 0,0154;

- Upoređivanjem alternativa, tj. dobavljača na osnovu svakog kriterijuma ponaosob, zaključeno je da je najbolja opcija po preduzeće na osnovu kriterijuma kvalitet proizvoda alternativa $\mathrm{A}_{3}$. Dalje, na osnovu kriterijuma cena, najpovoljniji dobavljač je $\mathrm{A}_{2}$, dok je na osnovu kriterijuma troškovi transporta najpogodniji dobavljač $\mathrm{A}_{3}$. $\mathrm{Na}$ osnovu kriterijuma rok isporuke, najpogodniji dobavljač je $\mathrm{A}_{4}$, dok najbolji asortiman poseduje dobavljač $A_{1}$. Prema kriterijumu pouzdanost, najbolje rezultate pokazao je dobavljač $\mathrm{A}_{2}$, dok je finansijski najstabilniji dobavljač $A_{3}$. Kada sagledamo tehnološku sposobnost, potrebno je napomenuti da su najbolji rezultati zabeleženi kod dobavljača $\mathrm{A}_{3}$. Proizvodi dobavljača $\mathrm{A}_{4}$ su u najvećoj meri usaglašeni sa ekološkim standardima, dok je sa aspekta geografske udaljenosti najpovoljniji dobavljač $\mathrm{A}_{3}$;

- Sagledavajući sve faktore, potrebno je napomenuti da se kao najpovoljniji dobavljač istakao dobavljač $\mathrm{A}_{3}$ sa ocenom 0,3644 , dok je najmanje povoljan dobavljač sa aspekta razmatranih kriterijuma dobavljač $\mathrm{A}_{1}$ sa ocenom 0,1754.

U cilju sveobuhvatnosti problema izbora dobavljača, kao esencijalnog pitanja poslovanja privrednog subjekta u modernom vremenu privređivanja, korišćen je softverski paket Expert Choice. Primena ovog softvera potvrdila je rezultate istraživanja i dala važnu potporu uspešnom poslovanju razmatranog privrednog subjekta. 


\section{LITERATURA}

[1] D. Kannan, R. Khodaverdi, L. Olfat, A. Jafarian, A., Diabat, "Integrated fuzzy multi criteria decision making method and multi-objective programming approach for supplier selection and oreder allocation in a green supply chain," Journal of Cleaner Production. 47, pp. 355-367. 2013.

[2] J. Zak, "Comparative analysis of multiple criteria evaluatinos of suppliers in different industries," Transportation Research Procedia. 10, 2015, pp. 809-819.

[3] S. Gold, A. Awasthi, "Sustainable global supplier selection extended towards sustainability risks from $(1+n)$ th tier suppliers using fuzzy AHP based approach," IFAC-Papers Online. 48(3), pp. 966-971, 2015.

[4] L. De Boer, E. Labro, P. Morlacchi, "A review of methods supporting supplier selection," European Journal of Purchasing \& Supply Management, 7(2), pp. 75-89, 2001.

[5] H. Y. Wu, G. H. Tzeng, Y. H. Chen, "A fuzzy MCDM approach for evaluating banking performance based on Balanced Scorecard," Expert Systems with Applications, 36 (6), 2009, pp. 1013510147.

[6] L. De Boer, L. Van der Wegen, J. Telgen, "Outranking methods in support of supplier selection," European Journal of Purchasing \& Supply Management, 4(2), pp. 109-118, 1998.

[7] D. Castro-Lacouture, A. L. Medaglia, M. Skibniewski, "Supply chain optimization tool for purchasing decisions in B2B construction marketplace," Automation in Construction. 16(5), 569-575, 2007.

[8] F. L. Lima Junior, L., Osiro, L. C. R. Carpinetti, “A comparasion between fuzzy AHP and fuzzy TOPSIS methods to supplier selection," Applied Soft Computing. 21, pp. 194-209, 2014.
[9] G. W. Dickinson, "An analysis of vendor selection systems and decisions," Journal of Purchasing and Supply Management. 2(1), pp. 5-17, 1966.

[10] C. A. Weber, J. R. Current, W. C. Benton, "Vendor Selection Criteria and Methods," European Journal of Operational Research, 50(1), 1991, pp. 2-18.

[11] S. Talluri, S., R. Narasimhan, "Vendor Evaluation with performance variability: A max-min approach," European Journal of Operational Research, 146(3), 2003, pp. 543-552.

[12] D. R. Lehmann, O. Shaugnessy, "Decision criteria used in buying different categories of products," Journal of Purchasing and Materials, 18(1), pp. 9-14, 1982.

[13] J. R. Caddick, B. G. Dale, "The determination of purchasing objectives and strategies: some key influences," International Journal of Physical Distribution and Materials Management, Vol. 17 Issue: 3, pp. 5-16, 1987.

[14] Š. Bajrami, "ELECTRE i AHP - sistemi za podršku višekriterijumskom odlučivanju," XIII međunarodni naučno-stručni simpozijum INFOTEH-JAHORINA, 2014, str. 599-604.

[15] B. Srđević, Z. Srđević, K. Suvočarev, "Kompjuterski alati i sistemi za podršku u poljoprivredi," Letopis naučnih radova Poljoprivrednog fakulteta, 31(1), 2007, str. 55-64.

[16] T. L. Saaty, The Analytic Hierarchu Process, New York: McGraw Hill International, 1980, p. 5.

[17] G. Polat, E. Eray, "An integrated approach using AHP-ER to supplier selection in railway projects," Procedia Engineering, 123, pp. 415-422, 2015.

[18] Industry Computer Software Expert Choice, Inc. "Expert Choice (Version 11)," 2016. 


\title{
THE USAGE OF THE AHPAND EXPERT CHOICE SOFTWARE FOR MULTI-CRITERIA SUPPLIERS SELECTION
}

\begin{abstract}
:
Procurement function is one of the most important continent in particular economic operator. From the success of this function depends largely on the efficiency and effectiveness of the company. In today's market conditions, the process of selection of suppliers is one of the key activities under the management of procurement and supply chain environments. The task of all economic subjects, regardless of the activity is meeting the needs. In order to achieve this task, it is necessary to have good associates who are financially stable, deliver goods on time, have the goods of high quality that are sold at low prices. The subject of the research work is multi criteria selection of suppliers using the AHP methodology with the help of Expert Choice software package 11. The aim of the investigation is the ranking of suppliers based on defined criteria decision making.
\end{abstract}

Keywords:

procurement, supplier selection, AHP methodology, software Expert Choice 11 